sands of dollars being spent on ICU care for an elderly, desperately ill patient who, if he/she could voice an opinion, would ask, in contrast to Dylan Thomas's poem, to be allowed to "go gentle into that good night." It is a form of abuse to insist on intervention when it is not wanted and not justified. Those dollars need to go into preventive medicine, drug benefits, and social programs that teach healthy living skills to avoid chronic, preventable diseases like obesity, diabetes, and smoking-related lung cancer, not into respirator care for a 96-yearold man with aspiration-induced pneumonia who has begged to be allowed to die in peace. What happened to the old saying that pneumonia is an old man's best friend? The availability of sophisticated technologies doesn't mandate their use. Hard choices do need to be made - is an expensive biological therapeutic that may at best extend a life for six to eight weeks warranted for any patient when those dollars could instead be spent on well-baby clinic visits? The answer may be yes when the patient involved is a 40-year-old mother of three with breast cancer, but no when it is an 84-year-old man with metastatic prostate cancer. Who should make those decisions? The doctors, the patient, the family, and, if necessary, an institutional review board. Common sense should not be underrated. These issues do not translate into "death panels"; they speak to reality and to fair play - and to dignity at the end of life.

The public perception of medicine and doctors as white knights who are not allowed to fail must also be taken out of the closet, shaken down, dusted off, and revised. Since when did we believe that life is without risk? The reality is that any procedure, any drug is always a risk/benefit proposition. Those risks should be made utterly transparent and abundantly clear. And the inevitable disappointments that ensue when a drug has unfortunate side effects or a procedure doesn't go as hoped for should not translate into medical malpractice suits. That way leads to unnecessary tests and procedures that lead to spi- raling medical care costs. My elder son, a surgical resident at Massachusetts General Hospital, sees the waste every day. Talk to any doctor and they will tell you they are forced to order expensive tests solely to protect themselves against malpractice suits.

For goodness' sakes, let's give President Obama's plans a chance. Are they perfect? No. Are they visionary and courageous? Yes. Get on board, Republicans and Blue Dog Democrats, because we are headed for disaster with the status quo.

\section{Laurie H. Glimcher}

Harvard Medical School, Boston, Massachusetts, USA. E-mail: lglimche@hsph. harvard.edu.

Conflict of interest: Laurie H. Glimcher is on the Board of Directors of the Bristol-Myers Squibb Pharmaceutical Corporation.

J. Clin. Invest. 119:2858-2859 (2009). doi:10.1172/JCI40996.

\title{
Research and education in health care reform
}

$T_{0}$ o an observer, the periodic national argument over health care reform sounds sadly familiar. Rational discourse has given way to a noisy and dispiriting exchange of sound bites and rigid ideology. Special interest groups, including insurers and drug companies, have already made their deals to preserve their economic advantage, with hospitals and physician groups hoping for similar treatment. The usual goals of health care reform - improved access, improved health care outcomes, and decreased cost - remain elusive, with increased access the only goal likely to emerge from current legislative negotiations. In every previous effort at reform, organized medicine used its considerable influence to undermine improvements in our health care system that would have benefited patients. Now, the more-disorganized and less-influential profession of medicine seems less able to shape policy or legislation for either the profession's selfinterest or the public interest.

In the midst of this disarray, the diminished status of academic medicine and the biomedical research community is notable. The central importance of research and education, and especially their impact on the practice of medicine, does not seem to enter the debate. Only the exaggerated claims for "comparative effectiveness" research appear to have any meaningful role in ongoing discussions and current policy formulations. Yet it is likely that the success of health care reform will depend more than is now recognized on whether medicine broadly, and internal medicine specifically, can assert its leadership in linking health reform to fundamental changes in clinical education and clinical discovery research.

Nearly every discussion of health care reform emphasizes the need for greater primary care and the more judicious use of health care resources by physicians. Internal medicine is central to achieving both of these goals. For the past 50 years, internal medicine has been the front door to medical care for almost all adult patients; it has been the backbone of education for medical students, residents, and fellows training in the subspecialties; and it is also the engine for the nation's biomedical research programs. Since neither medical schools nor teaching hospitals have been able to focus the health care debate on changes that would have lasting benefit for the health of the public, it falls to the field of internal medicine to reframe the debate in ways that would achieve meaningful reform.
Sadly, the desultory state of education and training in internal medicine illustrates the reasons for the diminished stature of academic medicine more broadly. Medical students unabashedly seek the "ROAD to happiness" with careers in the lifestyle-friendly specialties of radiology, ophthalmology, anesthesiology, and dermatology. While admittedly needed specialties, their disproportionate popularity reflects a shared failure of national health policy (including reimbursement policies), medical school education, and internal medicine training. While changes are desperately needed to deal with the first two failings as part of health care reform, the experience of the last several decades and the current debates suggest that substantive modifications are unlikely. Internal medicine training is the only one for which we in the academic internal medicine community have direct oversight. Yet here too we have failed both our students and the public. What can we do to ensure that the road to happiness for medical students is also the path to renewal for the profession of medicine?

Internal medicine, including its academic departments and professional organizations, 
must reinvigorate educational programs for both clinical care and clinical discovery research. In clinical education, practitioners of internal medicine should recommit to our traditions even as we embrace contemporary medical science and clinical practice improvements. As an academically based specialty, internal medicine has neglected the still-modern principles of diagnostic parsimony and therapeutic proficiency that have always distinguished the admired internist. It is not too late to emphasize again clinical care rooted in sound bedside skills and a scholarly approach to practice, further enriched by a deep appreciation for the influence of social and environmental factors on the risk for disease and the response to treatment. It is not too late, either, for our field to lead rather than follow the initiatives of this "global generation," which is dedicated to local and worldwide improvements in human health. These goals cannot be met if we continue to delegate the education of our students and trainees to our most junior, though talented, faculty. Senior faculty and physician-scientists who have fled the wards where students are inspired to choose careers in internal medicine and to adopt the values of our discipline must engage again if we are to realize the renewal of internal medicine and the long-term success of health reform.

Educational change is needed as well to inspire students and trainees to pursue clinical discovery research. Clinical discovery includes the translation of laboratory science to clinical care, as well as the clinical epidemiology and health services research that was "invented" by academic general internal medicine. Ironically, despite its leadership in developing these fields, which constitute the basic science of clinical practice, doctors practicing internal medicine have not succeeded in integrating these research achievements into either clinical education or clinical care. Health reform goals of decreased cost and improved outcomes depend on leadership from the field of internal medicine for advances in clinical discovery research that also advance human health. Without these commitments to innovation in education and research, health care reform will exchange improved access to care for worsening costs and quality.

In health care reform, government has responsibility for ensuring access to medical care for all Americans. Neither further policy analyses nor additional legislative actions will be sufficient to achieve either improved patient outcomes or diminished medical care costs. Achieving these goals is the responsibility of the profession of medicine. Internal medicine will need to lead in this effort by once again promoting effectiveness and efficiency as the hallmarks of medical care. In doing so, internal medicine will also have crafted a new and renewable social contract that holds the promise of delivering at last on our duty to always put the public interest ahead of our profession's self-interest.

\section{Ralph I. Horwitz}

Stanford University, Palo Alto, California, USA. E-mail: ralph.horwitz@stanford.edu.

J. Clin. Invest. 119:2859-2860 (2009). doi:10.1172/JCI41032.

\section{Build it and hope that enough of them will come}

$\mathrm{H}$ ealth care reform has been postponed for too long, and we all should be invested in seeing it succeed. Among other issues, there are workforce challenges that need to be solved. Where will we get the practitioners needed to provide accessible, highquality care to our aging population? How will we deal with the increasing amount of time it takes to become a fully trained physician? Will different approaches to care and reimbursement make medicine a less appealing profession in the future?

There are already too few primary care practitioners in many communities, and the shortage is projected to get worse. I don't think American medical schools can (or should) increase capacity to turn out enough primary care doctors to fix this problem. Even if classes were dramatically enlarged, there is no guarantee that the added medical students would choose primary care. A better approach would be to redefine the responsibilities of generalist and specialist physicians and allow other professionals - physician assistants, nurses, other extenders - to play bigger roles in delivering and coordinating care. If we are going to solve our future health care needs, medical education will need to do more to prepare students for working collaboratively as members of health care teams. Ideally, students preparing for careers in the various health professions should interact through joint educational experiences that foster mutual respect and understanding. We need to let go of the traditional hierarchy and the view that a physician must always be the person in charge. We should invest in training programs and career development for non-MD practitioners.

Clinical education has been impacted by revving up RVU (relative value units) expectations, regulating resident work hours, and shifting more patient care to ambulatory settings. It is difficult to cram in enough teachable moments and observations of disease progression. Concerns about litigation have led to increased oversight of residents and fellows by attending physicians. For all of these reasons, it takes young doctors longer to become fully trained and independent, which indirectly increases the cost of producing each new physician, both for individuals and for society. I think it's time to look at this problem in a new way.
One approach might be to reevaluate our one-size-fits-all curriculum. Each student is expected to master a defined body of material in college and in medical school, regardless of whether she or he intends to become a surgeon, a bench scientist, or a pediatrician. I'd like to see thoughtful exploration of alternative models, e.g., partitioning medical education into separate content tracks for surgeons, for generalists, for investigators, and so on. This would be analogous to PhD programs, which require students to differentiate early in their predoctoral education. Recognizing that most students aren't exposed to behind-the-scenes aspects of medical practice before entering medical school, a new curriculum might start with an introductory clinical experience that allows students to sample different physician careers before committing to a more specialized program. Tracks might begin early in medical school and extend through residency. Such an approach would not only decrease the period of training, but it might also create late-entry and reentry options for those who have delayed or interrupted their pro- 